\title{
Ensino da bioética nos cursos de Enfermagem das universidades federais brasileiras
}

José Carlos Ferreira Couto Filho ${ }^{1}$, Flávia Silva Souza ${ }^{2}$, Sylvia Sardinha da Silva ${ }^{3}$, Sérgio Yarid ${ }^{4}$, Edite Lago da Silva Sena ${ }^{5}$

\section{Resumo}

Trata-se de artigo de pesquisa documental voltado a identificar a oferta da disciplina ou da temática bioética nos cursos de graduação em Enfermagem das universidades federais brasileiras. Adotou-se como critério básico de seleção de amostra a disponibilização online do projeto político-pedagógico do curso de Enfermagem. Foram identificadas 16 instituições (27\%) que atendiam ao critério, e a bioética constava na grade curricular ou era apresentada como temática específica em oito delas (50\%). A outra metade da amostra não oferta a disciplina ou discute transversalmente o tema, embora sete cursos $(43,75 \%)$ ofereçam disciplinas correlatas: ética; legislação em enfermagem; exercício da enfermagem; deontologia. Verificou-se que um curso (6,25 \%) não oferta nenhuma disciplina referente à temática. A falta de padronização curricular em relação à oferta da disciplina permite concluir que a formação profissional em enfermagem é prejudicada e que isso também estabelece discrepância entre os cursos das diferentes instituições.

Palavras-chave: Bioética. Ética. Ensino da enfermagem.

\section{Resumen}

\section{Estudio de la enseñanza de bioética en los cursos de Enfermería de universidades federales brasileñas}

Se trata de artículo de investigación documental como objetivo identificar la presencia de la disciplina o de la temática bioética en los cursos de grado en enfermería de las universidades federales brasileñas. Adoptando como criterios basico de selección de la muestra, solamente las universidades que pusieron a disponibilidad de forma online los Proyectos Políticos Pedagógicos del curso de Enfermería. Fueran identificadas 16 (27\%) universidades federales, de entre las cuales ocho ofrecen la Bioética como componente curricular o temática específica (50\%). La otra mitad de la muestra no ofrecen la disciplina Bioética o temática relacionada, siendo que siete de esas $(43,75 \%)$ abordan temáticas correlacionadas: ética, legislación en enfermería, ejercicio de la enfermería y deontología. Una universidad $(6,25 \%)$ no aborda la temática. La falta de padrones curriculares en relación a oferta de la disciplina permite concluir que la formación profesional en enfermaría es perjudicada e que esto también establece discrepancia entre los cursos de las diferentes instituciones.

Palabras-clave: Bioética. Ética. Enseñanza de enfermería.

\section{Abstract}

\section{Survey of bioethics teaching in Nursing Courses of Brazilian Federal Universities}

This documentary research paper aims to identify the presence of bioethics, or Bioethical related themes, as subject matter in under graduation nursing courses of Brazilian Federal Universities. Adopting as inclusion criteria for the selection of the sample only the universities which provided online the Pedagogical Political Projects of the Nursing Courses. We identified in the collected results from 16 (27\%) Federal Universities, that eight Universities have Bioethics as curriculum component or specific theme (50\% of the total number) of, and that there is no Bioethics or bioethical related themes teaching, in the other eight universities. Seven of these Universities (43.75\%), address the following issues: ethics, nursing law, nursing practice and deontology. And one university (6.25\%) does not address the issue. It is concluded that the subject matter bioethics and/or bioethical related themes, are not present in all curricula of the Brazilian Federal Universities nursing courses identified in this study.

Key words: Bioethics. Ethics. Nursing teaching.

1. Mestrando zecaferreirafilho@hotmail.com 2. Mestranda flaviameg@bol.com.br 3. Mestranda sylviasardinha@hotmail.com 4. Doutor syarid@hotmail.com 5. Doutora editelago@gmail.com - Universidade Estadual do Sudoeste da Bahia (Uesb), Jequié/BA, Brasil. 
A bioética teve como um de seus principais fatores desencadeadores o avanço biotecnológico, especialmente na segunda metade do século XX. A contemporânea tecnologia deu novos poderes ao homem, afetando seu modo de agir e instaurando um ritmo diferente daquele que determinava as transformações de métodos e técnicas do passado ${ }^{1}$. Por isso, os temas e situações conflituosas na área da saúde estão, na maioria das vezes, relacionados aos avanços científicos e ao desenvolvimento tecnológico ${ }^{2}$. Em decorrência, enfatiza-se a importância da educação e formação em bioética, que é, antes de tudo, um processo de sensibilização e capacitação voltado ao desenvolvimento dos valores associados ao exercício da cidadania ${ }^{3}$.

Nesse sentido, ao refletir teoricamente sobre o ensino da ética e da bioética, entende-se que a construção de um novo conhecimento, competências, atitudes e habilidades no exercício profissional da enfermagem deve ter por fundamentação as concepções teóricas dos campos da ética e da bioética, aplicadas à construção da consciência moral. Esse processo pedagógico, refletido e vivido pelos alunos de graduação, pode ser capaz de habilitá-los a atuar profissionalmente frente à pluralidade cultural da vida em sociedade ${ }^{4}$.

Conforme $o$ artigo $3^{\circ}$ das Diretrizes Curriculares Nacionais do Curso de Graduação de Enfermagem (Resolução CNE/CES 3), o ensino da enfermagem tem por objetivo a formação de profissionais qualificados, com formação generalista, humanista, crítica e reflexiva, pautada em princípios éticos e no rigor técnico, científico e intelectual ${ }^{5}$. Essas orientações destinam-se a formar profissionais capazes de dedicar-se ao exercício da enfermagem e atuar de maneira efetiva e responsável neste mister.

Para tanto, é importante que durante o processo de formação sejam facultados conhecimentos que possibilitem sua atuação futura, o que facilita o gerenciamento do processo de trabalho, considerando, especialmente, a aplicação da reflexão bioética à enfermagem. Aqui, considera-se bioética a vertente da ética aplicada que mais simula a condição humana atual, por dizer respeito aos principais conflitos que surgem na prática profissional diária. A bioética induz à reflexão que, por sua vez, estimula a resolubilidade dos conflitos tanto em nível individual como coletivo, em todos os âmbitos de atuação profissional ${ }^{6}$.

Considerando que a formação profissional não pode reduzir-se a incrementar o conhecimento deontológico, mas deve incorporar aprendizagens que permitam o desenvolvimento ético e moral do educando como pessoa, quer em sua dimensão individual quer social ${ }^{7}$, este artigo tem por objetivo identificar a presença da disciplina Bioética ou da temática bioética nos cursos de graduação em enfermagem das universidades federais brasileiras. Acreditamos que a reflexão bioética nestes cursos, possibilitada pela introdução de conceitos, bem como a identificação de sua relevância na assistência, ensino e pesquisa é essencial à prática profissional autônoma, resolutiva e humanizada.

\section{Método}

Trata-se de artigo de pesquisa documental ${ }^{8}$, baseada em levantamento sistemático do projeto político-pedagógico (PPP) do curso de Enfermagem, disponibilizado em versão online nos sites das universidades federais. Ressalte-se que o referido PPP é o documento oficial que contém a proposta educativa para a formação profissional do estudante.

O universo de pesquisa foi composto pelas 58 universidades federais brasileiras e a amostra selecionada contou com 16 universidades ( $27 \%$ do total) que atendiam os critérios de seleção adotados. O primeiro dos quais, que definiu a inclusão na amostra, foi a existência online dos PPP do curso de Enfermagem em formato de documento de texto ou em Portable Document Format (PDF). O segundo critério refere-se à existência dos seguintes itens no PPP online: 1) ementa do componente curricular; 2) indicação do semestre do qual faz parte; 3 ) carga horária da disciplina.

A pesquisa foi realizada no período de 7 a 20 de junho de 2012 e as informações obtidas foram organizadas segundo a seguinte sequência metodológica: levantamento das universidades federais brasileiras; levantamento dos dados encontrados nos PPP dos cursos de Enfermagem; busca de identificação dos componentes curriculares que abordem a temática bioética, observando o nome de identificação, o semestre do qual faz parte, a carga horária e ementas.

\section{Resultados}

Na primeira etapa do trabalho foram localizadas 58 universidades federais, das quais 16 (27\%) selecionadas como amostra, de acordo com os critérios de inclusão supracitados, organizadas por suas respectivas regiões (Tabela 1 ). 
Tabela 1. Universidades federais brasileiras que oferecem curso de Enfermagem e disponibilizam o PPP online

\section{Região Nordeste}

Universidade Federal de Alagoas - Ufal

Universidade Federal da Bahia - Ufba

Universidade Federal do Ceará - UFC

Universidade Federal do Recôncavo da Bahia UFRB

Universidade Federal de Pernambuco - Ufpe

Fundação Universidade Federal do Piauí - Ufpi

Região Centro-Oeste

Fundação Universidade de Brasília - UnB

Universidade Federal de Goiás - UFG

Fundação Universidade Federal de Mato Grosso do Sul - UFMS

Tabela 2. Identificação do componente curricular disponibilizado no PPP online, suas cargas horárias e semestre

\begin{tabular}{|c|c|c|c|c|}
\hline Região Nordeste & $\begin{array}{l}\text { Identificação do componente } \\
\text { curricular }\end{array}$ & Ano do PPP & Semestre & $\mathrm{CH}$ \\
\hline Ufal & Enfermagem, Saúde e Sociedade II & 2007 & $2^{\circ}$ & 240 \\
\hline \multirow{3}{*}{ Ufba } & Ética e Bioética I & 2009 & $2^{\circ}$ & 34 \\
\hline & Seminários de Ética e Bioética I & - & $5^{\circ}$ & 17 \\
\hline & Seminários de Ética e Bioética II & - & $8^{\circ}$ & 17 \\
\hline \multirow{2}{*}{ UFC } & Ética & 2004 & $1^{\circ}$ & 32 \\
\hline & Ética e Legislação em Enfermagem & & $5^{\circ}$ & 64 \\
\hline UFRB & Bioética e o Exercício da Enfermagem & Não identificado & $3^{\circ}$ & 68 \\
\hline \multirow{2}{*}{ Ufpe } & $\begin{array}{c}\text { Legislação de Enfermagem, Ética e } \\
\text { Bioética I }\end{array}$ & 2010 & $1^{\circ}$ & 30 \\
\hline & $\begin{array}{c}\text { Legislação de Enfermagem, Ética e } \\
\text { Bioética II }\end{array}$ & - & (eletivo) & 15 \\
\hline Ufpi & $\begin{array}{c}\text { Bioética, Ética e Legislação para } \\
\text { Enfermagem }\end{array}$ & Não identificado & $5^{\circ}$ & 45 \\
\hline $\begin{array}{l}\text { Região Centro- } \\
\text { Oeste }\end{array}$ & $\begin{array}{l}\text { Identificação do componente } \\
\text { curricular }\end{array}$ & Ano do PPP & Semestre & $\mathrm{CH}$ \\
\hline UnB & Ética, Bioética e Legislação & 2008 & $5^{\circ}$ & $4 \mathrm{CIC}$ \\
\hline UFG & Ética e Exercício da Enfermagem & Não identificado & $7^{\circ}$ & 40 \\
\hline UFMS & $\begin{array}{l}\text { Unidade Temática: 1.2- A Ética no Agir } \\
\text { Profissional do Enfermeiro }\end{array}$ & 2004 & $1^{\text {a SEP }}$ & 68 \\
\hline
\end{tabular}

Região Sudeste

Universidade Federal do Espírito Santo - Ufes

Universidade Federal de Minas Gerais - UFMG

Fundação Universidade Federal de São Carlos -

UFSCar

Fundação Universidade Federal de Uberlândia -

UFU

Universidade do Rio de Janeiro - UniRio

Universidade Federal do Rio de Janeiro - UFRJ

A segunda e terceira etapas da pesquisa foram empreendidas por meio do levantamento dos dados encontrados nos PPP dos cursos de Enfermagem e pela busca de identificação dos componentes curriculares que abordassem a temática bioética. Para isso, foi observado o nome de identificação do componente curricular, o semestre do qual faz parte, a carga horária e as ementas. Os resultados obtidos nessas etapas são apresentados na Tabela 2, na qual se pode observar os componentes curriculares; o semestre em que são ministrados e suas respectivas cargas horárias, possibilitando identificar-se, ainda, quando disponível, o ano de elaboração do PPP.
Universidade Federal Fluminense - UFF 


\begin{tabular}{|c|c|c|c|c|}
\hline Região Sudeste & $\begin{array}{l}\text { Identificação do componente } \\
\text { curricular }\end{array}$ & Ano do PPP & Semestre & CH \\
\hline \multirow{3}{*}{ Ufes } & Introdução ao Contexto da Enfermagem: & 2010 & & \\
\hline & Ética & - & $1^{\circ}$ & 30 \\
\hline & Legislação e Deontologia & - & $1^{\circ}$ & 30 \\
\hline UFF & $\begin{array}{c}\text { Relações de Trabalho em Saúde: Ética, } \\
\text { Bioética e Legislação Profissional }\end{array}$ & 2005 & $3^{\circ}$ & 60 \\
\hline \multirow{2}{*}{ UFMG } & Bioética & 2006 & Optativa & 45 \\
\hline & Ética e Cultura & - & Optativa & 15 \\
\hline UFSCar & $\begin{array}{l}\text { Núcleo de Bases Históricas, Éticas e } \\
\text { Legais da Enfermagem }\end{array}$ & 2004 & $1^{\circ}$ & 60 \\
\hline UFU & Ética e Antropologia Filosófica & 2010 & $1^{\circ}$ & 45 \\
\hline Unirio & $\begin{array}{c}\text { Tópicos Especiais de Bioética em } \\
\text { Enfermagem }\end{array}$ & 2003 & Optativa & 30 \\
\hline \multirow{2}{*}{ UFRJ } & Ética Profissional & 2006 & $6^{\circ}$ & 15 \\
\hline & Deontologia da Enfermagem & - & $6^{\circ}$ & 15 \\
\hline
\end{tabular}

Fonte: Projetos político-pedagógicos (PPP) do curso de Enfermagem das universidades federais. Jequié/BA.

Ao analisar o PPP do curso de enfermagem, identificou-se que a abordagem da temática bioética permeia cinco eixos de discussão nas ementas levantadas: 1) bioética; 2) ética; 3) legislação em enfermagem; 4) exercício da enfermagem e; 5) deontologia. Como foram identificadas oito universidades federais que apresentam a bioética como componente curricular ou temática específica, isto equivale a dizer que $50 \%$ do total da amostra selecionada inclui o estudo de bioética na grade curricular.

Dentre as oito universidades que não possuem a disciplina Bioética nem se referem diretamente a este campo, sete $(43,75 \%$ do total da amostra selecionada) abordam temáticas correlacionadas: ética; legislação em enfermagem; exercício da enfermagem e deontologia. Apenas uma universidade $(6,25$ do total) não aborda a temática nem direta nem indiretamente. Vale ressaltar que no estudo observado nas instituições selecionadas somente o curso de Enfermagem da UFMG aborda de maneira exclusiva a bioética como componente curricular, ainda que na modalidade optativa, e as outras sete a oferecem como matéria integrante de dez cursos.

\section{Discussão}

Ao analisar as ementas da disciplina Bioética ou esta temática nos PPP dos cursos de Enfermagem das universidades federais, observou-se que o estudo do campo nestas instituições incorpora desde sua conceituação, origem, característica, princípios e aplicabilidade em enfermagem até temas e dilemas bioéticos relativos ao exercício da profissão. A análi- se da inserção da bioética nas propostas curriculares de $50 \%$ dos cursos de Enfermagem parece indicar a necessidade desta reflexão no ensino, valorizando sua singularidade temática e a pertinência da inclusão desta reflexão na formação profissional e social.

A inserção da ética além da bioética no currículo integrado de enfermagem traz contribuições relevantes para o ensino nesta área do conhecimento. Essa conclusão pode ser inferida pelo fato de $93,75 \%$ dos cursos dedicarem ao menos um semestre a estudos deste teor. Tal inclusão possibilita criar momentos de discussão e reflexão ética durante todo o processo de construção curricular, permitindo novo modelo de ensino que valorize a tomada de decisão em situações práticas do cuidar em enfermagem. Tal modelo confronta-se com o molde tradicional de ensino, no qual a estrutura curricular volta-se prioritariamente aos aspectos técnicos da prática da enfermagem, acabando, assim, por limitar o conhecimento ético a uma incipiente base teórica e deontológica ${ }^{9}$, o que deixa a descoberto os aspectos essenciais da vida profissional voltados à dimensão ética.

Frequentemente, as questões dilemáticas em saúde envolvem a reflexão sobre a vida e a morte. Ainda que as decisões profissionais relacionadas a tais questionamentos sejam pautadas por ditames técnicos, suas repercussões no íntimo dos profissionais são fortemente influenciadas por seus valores morais, formação familiar e convicção religiosa ${ }^{2}$. Em decorrência desse background, durante o curso de graduação o acadêmico de Enfermagem provavelmente vivenciará experiências conflituosas - mas não está preparado para se posicionar ante as mesmas. Esse tipo de situação, que em alguns casos 
chega a ser frequente ou até cotidiana na vida laboral, pode produzir intenso sofrimento psíquico e moral no futuro profissional.

Para enfrentar essa circunstância adversa, é importante que o aluno de graduação compreenda, em primeiro lugar, que os problemas práticos da saúde decorrem, em grande medida, das disparidades socioeconômicas que marcam a realidade brasileira, a qual foi produzida em meio à diversidade sóciohistórico-cultural. Esta perspectiva, estimulada na reflexão bioética, auxilia o futuro profissional a entender os determinantes sociais do processo saúdeadoecimento, possibilitando-lhe atuar de maneira respeitosa frente às diferenças culturais e sociais dos usuários. Poderá também compreender que discutir o exercício profissional da enfermagem à luz da ética e da bioética estimula sua capacidade de agir conscientemente, de forma crítica e ponderada ${ }^{10}$, possibilitando uma atuação profissional consciente e reflexiva, pautada pelos princípios de cidadania. É exatamente por isso que na prática do ensino superior da enfermagem a bioética e a ética são componentes curriculares fundamentais, dado propiciarem esse tipo de reflexão, voltada ao intuito de fazer pensar ${ }^{6}$.

Se a ética e a bioética se revelam importantes para a prática profissional cotidiana, seu valor cresce ainda mais quando se considera a evolução da ciência e o advento das novas tecnologias que trazem inéditos dilemas éticos e bioéticos, para os quais, na maioria das vezes, o enfermeiro também não foi preparado durante a sua formação acadêmica. Essa situação reforça a necessidade de ministrar o ensino da bioética e buscar novas abordagens de fortalecer a formação profissional dos enfermeiros, com vistas a que sejam capazes de refletir sobre a maneira adequada de se conduzir na profissão com competência, comprometimento e responsabilidade. Os impasses decorrentes das novas tecnologias não apenas exigem o aprimoramento técnico dos profissionais como revelam a importância de sua formação ética.

Estudo de Mascarenhas e Santa Rosa, em 2010, se aproxima da realidade da pesquisa adscrita. Aquele trabalho observou que o ensino da ética está direcionado para a abordagem da deontologia no exercício profissional. $O$ estudo encontrou também a inclusão de fundamentos de ética e bioética nas propostas curriculares, ainda que em menor proporção. Se o conhecimento das regras éticas para o exercício profissional é indispensável à plena capacitação, a reflexão ética e bioética revela-se essencial para a formação de enfermeiros capazes de manejar os conflitos cotidianos; profissionais que tenham embasamento teórico pertinente para a tomada de decisões frente aos constantes dilemas de ordem ética com que se deparam ${ }^{11}$.

No tocante à afirmação acima, faz-se indispensável analisar em que semestre acadêmico a disciplina bioética é ministrada em cada um dos cursos, bem como sua carga horária - dados que permitem imaginar a densidade do conteúdo ministrado. Ao analisar comparativamente os resultados das colunas 4 e 5 da Tabela 2, verifica-se que dentre as instituições de ensino que abordam a temática bioética em sua matriz curricular, quatro a ofertam nos semestres iniciais - destas, uma a situa no primeiro semestre; outra, no segundo semestre; duas no terceiro semestre e uma que apresenta a disciplina apenas no final do curso, no oitavo semestre. Observou-se também, em três instituições, que a oferta da temática bioética apresenta-se como disciplina optativa - e em apenas uma, como eletiva.

Vale enfatizar que dentre as instituições de ensino pesquisadas a UFBA se destaca ao apresentar a temática em mais de um semestre, o que permite aos estudantes vivenciar a reflexão bioética sob diferentes prismas durante a formação. Mas esse destaque conferido pela instituição à bioética não é norma, pois em alguns cursos a disciplina é optativa, o que não torna obrigatório seu estudo ao discente de enfermagem. Observou-se, inclusive, a existência de um curso que não oferta qualquer disciplina ou discussão transversal da temática. Tal contingência, que limita a formação profissional do aluno, contribui para que não exista uma padronização mínima entre os diferentes cursos e instituições, no que tange à formação ética profissional. Essa falha, que com certeza traz efeitos adversos à formação individual, repercute na dimensão coletiva à medida que dificulta a consolidação de quadros profissionais capacitados para a reflexão ética na vida profissional - como exige a atual estrutura do Sistema Único de Saúde (SUS).

Desta constatação pode-se depreender que é de suma importância que a reflexão bioética seja ofertada ao aluno durante a sua formação em todos os cursos de graduação em Enfermagem, incorporação curricular que deve ser bandeira de reivindicação dos docentes junto a seus departamentos e instituições de ensino, bem como ao Ministério da Educação (MEC). Ressalte-se, ainda, que para o meIhor aproveitamento da reflexão bioética pelos discentes a disciplina deve ser apresentada desde os primeiros semestres da graduação, de preferência estendendo-se e aprofundando-se ao longo de todo o curso. Ou seja, a disciplina será mais bem aproveitada se ministrada continuamente - e antes do 
início das práticas de campo -, para assegurar aos alunos maior preparo no enfrentamento dos dilemas vivenciados na prática profissional.

É importante salientar que o estudo deparouse com uma dificuldade adicional, que diz respeito à avaliação do perfil de quem leciona a disciplina ou temática bioética, cujos dados não estão disponíveis na versão online dos PPP. Assim, foi impossível saber o grau de formação acadêmica do docente, se mestre ou doutor em ética e/ou bioética, o que impede o aprofundamento analítico do resultado da oferta da disciplina Bioética nos PPP. Considera-se relevante enfatizar a ausência desta informação, uma vez que a formação profissional do docente é fator de suma importância tanto na definição do conteúdo da disciplina quanto na forma como é ministrado.

Diretamente relacionada a esta questão, fazse necessário destacar que as informações disponibilizadas nos PPP online podem não espelhar literalmente a realidade educacional vivenciada na sala de aula. Essa diferença, que em parte pode ser explicada por entraves na necessária atualização semestral dos PPP pelas instituições, decorre adicionalmente do fato de a proposta do currículo formal ser tomada como um guia, em termos gerais, voltado a orientar a condução prática da disciplina. Nesse sentido, é fundamental ponderar que a prática educativa per se implica em adequações nas disciplinas a cada semestre, quer em decorrência de ser ministrada por docentes diferentes quer, especialmente, devido à incorporação de novos trabalhos acadêmicos que tenham acrescentado conhecimento ao estado da arte. Portanto, merece destaque o fato de os cursos universitários passarem por constantes adequações, ainda que não registradas no currículo das disciplinas.

Por fim, é preciso considerar que se essas adequações e ajustes na forma de ministrar a disciplina, ou mesmo seu conteúdo, em relação ao apresentado no PPP, concorrem para diminuir a abrangência das reflexões produzidas por um levantamento online, como o empreendido nesta pesquisa, isto não quer necessariamente dizer que os cursos estejam aquém do currículo divulgado. Mesmo que isto seja uma possibilidade, é mais provável que essas diferenças reflitam o movimento dialético entre o formal e o informal, indispensável à efetiva educação. Pode-se presumir que indiquem tensões e contradições entre o prescrito e o vivenciado; entre a regulação e a emancipação, que estão na base da formação profissional de qualidade, especialmente quando se tratam questões éticas e bioéticas relacionadas à saúde. Ou seja, se, por um lado, o cur- rículo oficial apresenta diversos objetivos a serem atingidos pelo processo educativo, por outro, o cotidiano impõe situações emergentes, que demandam uma prática pedagógica dinâmica, capazes de responder a estas necessidades ${ }^{12}$.

\section{Considerações finais}

Este estudo observou a presença da disciplina Bioética ou tema bioética ministrada diretamente em $50 \%$ das universidades pesquisadas. Nota-se, porém, que a bioética ainda é trabalhada como tema complementar de outras disciplinas e não como foco central do processo de ensino-aprendizagem na formação de bacharéis em Enfermagem. Disto se conclui ser necessária a inserção da bioética no contexto educativo dos cursos de Enfermagem como disciplina autônoma. É imprescindível estabelecer espaços para a discussão bioética acerca dos conflitos éticos que envolvem a profissão, considerando, especialmente, a necessidade de estimular a reflexão e o diálogo frente àquelas situações dilemáticas não pautadas somente nos valores inerentes à profissão, que são de natureza normativa, mas nas que abrangem a dimensão íntima do indivíduo, suas crenças e moralidades ${ }^{2}$.

A importância de ampliar a qualificação dos trabalhadores de saúde nas dimensões técnica especializada, ético-política, comunicacional e de inter-relações pessoais para a participação como sujeitos integrais no mundo do trabalho é o grande desafio para a ocupação de espaços pela Enfermagem ${ }^{11}$. Frente às aceleradas transformações com as quais todos convivemos, em especial os profissionais da saúde, somos favoráveis à inclusão e fortalecimento nas grades curriculares de uma bioética que se oriente pelo respeito e incentivo à liberdade individual na tomada de decisão, adicionada dos princípios da solidariedade, da justiça, da equidade e da responsabilidade, reforçando a necessidade de proteger os mais desfavorecidos e frágeis, vulneráveis ou vulnerados ${ }^{1}$.

Portanto, é de fundamental relevância que se intensifique a abordagem humanística nos cursos de Enfermagem, valorizando a interdisciplinaridade e a utilização da bioética como componente curricular obrigatório, devido a sua relevância significativa na assistência e no ensino. Desta forma se estarão formando profissionais atuantes, críticos e preparados cientificamente, com capacidade de relacionar teoria e prática em sua ação diária, levando ao desenvolvimento de visões críticas sobre as práticas de saúde em nosso país. 


\section{Referências}

1. Fortes PAC. A bioética em um mundo em transformação. Rev bioét (Impr.). 2011;19(2):319-27.

2. Rates CMP, Pessalacia JDR. Posicionamento ético de acadêmicos de Enfermagem acerca das situações dilemáticas em saúde. Rev bioét (Impr.). [internet]. 2010 [acesso 19 jul. 2012];18(3):659-75. Disponível: http://revistabioetica.cfm.org.br/index.php/revista_bioetica/ article/viewArticle/592

3. Silva PF. Educação em bioética: desafios na formação de professores. Rev bioét (Impr.). 2011;19(1):231-45.

4. Araújo JL, Jorge MSB, Freitas CHA, Moreira TMM. O ensino da ética e da bioética no processo de formação do enfermeiro frente às diretrizes curriculares nacionais. Cogitare Enfermagem. [internet]. 2009 [acesso 20 jul. 2012];14(3). Disponível: http://ojs.c3sl.ufpr.br/ojs2/index.php/ cogitare/article/view/16190/1070

5. Conselho Nacional de Educação. Câmara de Educação Superior. Resolução $n^{\circ} 3$, de 3 de abril de 2001. Estabelece normas para funcionamento de cursos de pós-graduação. Diário Oficial da União. 9 nov. 2001; Seção 1:37.

6. Barreto NAC, Silva KV, Araújo EC. Importância da bioética na formação do enfermeiro para o atendimento do adolescente enfermo crônico. Reme - Rev Min Enferm. [internet]. 2007 [acesso 4 jun. 2012];11(2):205-9. Disponível: http://www.revenf.bvs.br/scielo.php?script=sci_arttext\& pid=S1415-27622007000200016\&lng=pt.

7. Schuh $\mathrm{CM}$, Albuquerque IM. A ética na formação dos profissionais da saúde: algumas reflexões. Rev bioét (Impr.). [internet]. 2009 [acesso 19 jul. 2012];17(1):55-60. Disponível: http:// revistabioetica.cfm.org.br/index.php/revista_bioetica/article/viewArticle/79

8. Gil AC. Métodos e técnicas de pesquisa social. 6a ed. São Paulo: Atlas; 2008.

9. Pessalacia JDR, Oliveira VC, Rennó HMS, Guimarães EAA. Perspectivas do ensino de bioética na graduação em enfermagem. Rev Bras Enferm. [internet]. 2011 [acesso 16 jul. 2012];64(2):393-8. Disponível: http://www.scielo.br/scielo.php?script=sci_arttext\&pid=S003471672011000200029\&lng=en http://dx.doi.org/10.1590/S0034-71672011000200029.

10. Ito EE, Peres AM, Takahashi RT, Leite MMJ. O ensino de enfermagem e as diretrizes curriculares nacionais: utopia $x$ realidade. Rev Esc Enferm USP. [internet]. 2006 [acesso 16 jul. 2012];40(4):570-5. Disponível: http://www.scielo.br/scielo.php?script=sci_arttext\&pid=S008062342006000400017\&lng=en. http://dx.doi.org/10.1590/S0080-62342006000400017.

11. Mascarenhas NB, Santa RDO. Ensino da bioética na formação do enfermeiro: interface com a bibliografia adotada. Acta Paul Enferm. [internet]. 2010[acesso31jul.2012];23(3):392-8. Disponível: http://www.scielo.br/scielo.php?script=sci_arttext\&pid=S0103-21002010000300013\&lng=en http://dx.doi.org/10.1590/S0103-21002010000300013

12. Felicio HMDS. A instituição formal e a não formal na construção do currículo de uma escola de tempo integral. Educ Rev. [internet]. 2011 [acesso 3 dez. 2012];27(3). Disponível: http://dx.doi. org/10.1590/S0102-46982011000300009.

\section{Participação dos autores}

José Carlos Filho, Flávia Souza e Sylvia Silva desenharam e empreenderam a pesquisa, além de redigir o artigo. Sérgio Yarid e Edite Sena orientaram a elaboração do trabalho.

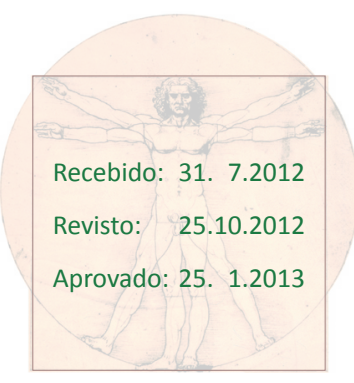

